\title{
COLAGEM AUTÓGENA DE FRAGMENTO EM DENTES ANTERIORES
}

\section{FRATURADOS}

Juliana Cristina RAMPAZZO, Jeisemar Sidney RAMPAZZO JUNIOR, Cintia Gaio MURAD, Cyntia Junqueira RIGOLON

A perda da estrutura dental ocorre com freqüência por meio de trauma dental, muitas vezes resultado de atividades esportivas, quedas e acidentes com bicicletas, skates, patins ou em outras atividades de lazer, sendo mais comum a fratura dos dentes anteriores com maior incidência entre sete e onze anos de idade. Os tratamentos restauradores para dentes anteriores fraturados utilizados atualmente são: colagem do fragmento autógeno, restaurações diretas em resina composta, podendo-se associar pinos intradentinários e, por último, restaurações indiretas. A colagem é uma técnica direta e conservadora, que utiliza o fragmento do próprio dente fraturado para devolver sua função mastigatória e estética. Neste trabalho será apresentado um relato de caso, em paciente do gênero masculino, oito anos de idade, apresentando fratura oblíqua no elemento 21. A fratura comprometeu esmalte e dentina, sem envolvimento pulpar, e o tratamento restaurador utilizado foi a colagem autógena do fragmento do dente fraturado, com sistema adesivo e resina composta. Os resultados obtidos foram bastante satisfatórios, concluindo-se que esta técnica de colagem autógena de fragmento é um procedimento indicado por sua simplicidade, resultado estético e funcional satisfatório, bem como a primeira opção de tratamento para casos onde houver a presença de fragmento dental.

Palavras-chave: Colagem dentária, Fraturas dos dentes, Estética dentária. 